\title{
Facile Synthesis of Cu2+ doped ZnO via Thermal Spreading method: A Dual Role to Photocatalyst for Organic Dye Amaranth and Photoluminescence for Blue-Green Emission
}

S. R. Chitra ( $\sim$ chiyatds@gmail.com )

PKN Arts and Science College

S. Karthik Kannan

CMS College of Science and Commerce

G. Johnsy Arputhavalli

Coimbatore Institute of Technology

Mohd Shkir

King Khalid University

S. AlFaify

King Khalid University

\section{Research Article}

Keywords: PXRD, Rietveld refinement method, Photocatalyst, Photoluminescence

Posted Date: July 7th, 2021

DOl: https://doi.org/10.21203/rs.3.rs-671738/v1

License: (c) (1) This work is licensed under a Creative Commons Attribution 4.0 International License. Read Full License 


\section{Abstract}

In this work "solve two problems with one single action" strategy was implemented for degradation of industrial dye Amaranth and enhanced blue-green emission for opto-electronics applications in $\mathrm{Cu}^{2+}$ doped $\mathrm{ZnO}$ materials. The different concentrations (weight (wt) \%) of $\mathrm{Cu}^{2+}$ doped $\mathrm{ZnO}$ materials have been synthesized by the thermal spreading method. The as-prepared $\mathrm{ZnO}$ and $\mathrm{Cu}^{2+}$ doped $\mathrm{ZnO}$ materials have effectively confirmed by various spectroscopic methods. The crystalline phase, surface morphology, compositions of elements and energy bandgap were studied systematically enquired by PXRD, SEM, EDS and UV-vis spectroscopic analysis, respectively. With the dopant concentration, $18 \mathrm{wt} \%$ of $\mathrm{Cu}^{2+}$ doped $\mathrm{ZnO}$ revealed outstanding photocatalytic performance to the degradation of Amaranth under visible light irradiation with an efficacy of about $97 \%$. Likewise, $18 \mathrm{wt} \%$ of $\mathrm{Cu}^{2+}$ doped $\mathrm{ZnO}$ shows an strong blue-green emission at around $495 \mathrm{~nm}$ owing to the internal oxygen vacancies. The present work gives some clue; it may be used as a proficient photocatalyst for degradation of dyes and luminescent material for optoelectronics applications.

\section{Introduction}

In contemporary circumstances, the ecosystem suffers numerous deficiencies such as energy crisis and environmental destruction [1]. Moreover, the speedy germination of dye industries drives precarious pollutants without treating properly consequently it causes environmental pollution [2]. Among the industrial dye, Amaranth employed principally in the generation of consumer products including paints, textile, printing inks, papers and plastics [3, 4]. But, Amaranth dye has been not entirely degraded and professes contradictory influences on living organisms such as persistent and consumptive toxicity [4]. On the other hand, the conventional light sources such as incandescent lamp, fluorescent lamp, halogen lamp and so forth consuming more energy for illumination as well as emitting heat radiation during the illumination causes negative risk to growing the global warming $[5,6]$. Conversely, the opto-electronic devices specifically in light emitting diode (LED) could need minimum energy, limits $\mathrm{CO}_{2}$ discharge, huge illuminating enforcement and extended lifespan [6]. Consequently, exploration for peculiar and effective material with large photocatalysis efficacy and extraordinary luminescent character is a dominant attention to the today's researchers.

In modern times, inorganic nano-structured samples have become increasingly popular in energy crisis based research groups [7]. Among them the simple metal oxides such as $\mathrm{ZnO}, \mathrm{CuO}, \mathrm{MgO}, \mathrm{NiO}, \mathrm{BaO}$ and etc., these are extensively applicable in numerous inherent areas due to their remarkable physicochemical characteristics [8]. Specifically, zinc oxide ( $\mathrm{ZnO})$ is a crucial constituent of the inorganic group and applied in diverse distinctive applications such as photonics, spintronics, sensors, energy conversion, optoelectronics, photocatalytic and other fields on account of its phase pure wurtzite hexagonal structure, high thermal conductivity, sophisticated band gap $(3.3 \mathrm{eV})$, high exciton binding energy $(60 \mathrm{meV})$, huge chemical invariability, abundant and non-toxicity [9]. In general, the crystallinity, surface morphology, defects in crystal and optical band gap are directly correlated to the activity of photocatalysis and photoluminescence [10]. Hence, many researches have progressed distinctive techniques for the fabrication of $\mathrm{ZnO}$ such as 
hydrothermal [11], sonochemical [12], solid state [13], surfactant-assisted [14] and thermal spreading [15] preparation technique. Among these, the thermal spreading synthesis method is one of the economical and easy to prepare the material. Besides the above-mentioned preparation methods, thermal spreading synthesis is one of the inexpensive and straightforward to prepare the material. Furthermore, the initiation of a foreign element into the semiconductor matrix, notably in the transition element is an active approach to achieve intensified photocatalytic and luminescence property. Among the transition metals, the divalent $\mathrm{Cu}^{2+}$ is the essential candidate because it is a prominent luminescence candidate which can enhance the luminescence of $\mathrm{ZnO}$ by creating localized impurity levels [16]. Likewise, the physical and chemical properties of copper are more similar to zinc which can modify the microstructure and the optical properties of the ZnO crystal system [17]. Recently, Alatawi et al., [18] reported on various dopant concentration of $\mathrm{Cu}^{2+}$ in $\mathrm{ZnO}$ using the hydrothermal method for the efficient photodegradation of methyl orange (MO) under solar irradiation. The enhanced photocatalytic activity of $\mathrm{Cu}$ doped $\mathrm{ZnO}$ nanorods via the vapour transport method for the degradation of resazurin (Rz) dye exposure by UV irradiation, reported by Rajneesh et al. [19]. Moreover, the strong green emission spectrum was attained by systematically Cu doped ZnO materials which are potentially important for photocatalytic and solar cell devices suggested by Sajjad et al., [20]. Raji et al., [21] suggest that the $\mathrm{Cu}^{2+}$ doped $\mathrm{ZnO}$ nanoparticles synthesized by co-precipitation technique can give the strong blue and green emissions which is a potential for use in white light emitting diodes.

We inspired by the preceding cases, tried an attempt to fabricate using the thermal spreading technique with a different dopant concentration of $\mathrm{Cu}^{2+}$ and study their photoluminescence and photocatalytic property. To fashionable our ability, this article is an open doorway of energy and environmental application of $\mathrm{Cu}^{2+}$ doped $\mathrm{ZnO}$ fabricated through the thermal spreading technique for intense blue-green emission as well as photodegradation of Amaranth.

\section{Materials And Methods}

\subsection{Preparation of $\mathrm{ZnO}: \mathrm{x}^{\circ} \mathrm{Cu}^{2+}(0,6,12,18$ and 24$)$ materials}

The pristine $\mathrm{ZnO}$ was synthesized based on the synthesis procedure reported by Sivaganesh et al., [9]. The equivalent molar ratio of zinc acetate and sodium hydroxide mixed to obtained $\mathrm{Zn}(\mathrm{OH})$. Under $400^{\circ} \mathrm{C}$ calcination, the phase pure $\mathrm{ZnO}$ was collected.

The synthesized product is referred to as pure $\mathrm{ZnO}$. The pristine $\mathrm{ZnO}$ was smashed alongside $\mathrm{CuO}$ to blend well completely with a help of mortar for 30 min. ZnO supported $x^{2} \mathrm{Cu}^{2+}(x=0,6,12,18$, and 24) was airdried using oven at $80^{\circ} \mathrm{C}$ with vacuum for $12 \mathrm{~h}$. The obtained blend was taken in a silica crucible covered with a lid and treated at high temperature in an enclosed muffle furnace at $600^{\circ} \mathrm{C}$ for $3 \mathrm{~h}\left(\mathrm{ramp} 8^{\circ} \mathrm{C} / \mathrm{min}\right)$ to accelerate thermal spreading. After a while the obtained material remained undisturbed until it gets cool to reach room temperature, the synthesized samples were utilized for additional characterizations. The different wt $\%$ of $\mathrm{Cu}^{2+}$ loaded as $\mathrm{ZnO}: \mathrm{x}^{2} \mathrm{Cu}^{2+}(0,6,12,18$ and 24$)$. 


\subsection{Characterization of $\mathrm{ZnO}: \mathrm{x}^{2} \mathrm{Cu}^{2+}(0,6,12,18$ and 24$)$ materials}

The Philips X'PERTPRO-powder diffractometer as an X-ray diffractometer was employed to estimate the phase purity of synthesized materials with the aid of CuKa monochromatic radiation in the range between $2 \theta=10-80^{\circ}$ with a step width of $0.02^{\circ}$. The surface morphology and composition of elements of prepared materials were measured by scanning electron microscope (SEM - Model: ZEISS - Sigma 300 microscope) and energy dispersive X-ray spectrometer (HORIBA EMAX X-ACT), respectively. The particle size was estimated using ImageJ software after digitalized capturing of various SEM images. JASCO FP-8500 Spectrofluorometer was handled to record the photoluminescence spectra of synthesized materials.

\subsection{Photodegradation of Amaranth using $\mathrm{ZnO}: \mathrm{x} \mathrm{Cu}^{2+}(0,6$, 12,18 and 24) materials}

The decomposition of the organic pollutant of Amaranth by the irradiation directly to the sunlight. In a 100 $\mathrm{mL}$ beaker, around $10 \mathrm{mg}$ of the as-prepared pure $\mathrm{ZnO}: \mathrm{x} \% \mathrm{Cu}^{2+}(\mathrm{x}=0,6,12,18$, and 24$)$ material was blended in a $50 \mathrm{~mL}$ amaranth solution. This resulting mixture could confirm the adsorption-desorption equilibrium of the Amaranth mixture for agitation for $30 \mathrm{~min}$ in dark conditions. From that point, the reaction mixture was moved to a petri dish volume containing $50 \mathrm{~mL}$. Collect the solution at every $20 \mathrm{~min}$ period breaks, for the investigation by using Ultraviolet-visible absorption spectroscopy. The catalyst was isolated with the help of high performed centrifuge and then washed relentlessly by using deionized water repeatedly and dehydrated at $60^{\circ} \mathrm{C}$. Finally, the recovered catalyst can be utilized for the reusability test. To get good and equal results, all the catalysts materials were performed at identical conditions.

\section{Results And Discussion \\ 3.1. Structural analysis}

The crystalline constitution of different wt \% of $\mathrm{Cu}^{2+}$ doped $\mathrm{ZnO}$ materials was investigated by powder Xray Diffraction (PXRD) analysis. The phase pure hexagonal structured $\mathrm{ZnO}$ was recognized with the standard JCPDS patterns [JCPDF card No. 36-1451] and the corresponding Bragg's peaks are well indexed as shown in Fig. 1. From Fig. 1 the characteristic diffraction peaks can be expertly coordinated to the hexagonal phase of $\mathrm{ZnO}$ with the space group of $\mathrm{P} 63 \mathrm{mc}$ (No.186). There were neither supplementary peaks were identified in the perceived PXRD profile which leads to each prepared materials are phase pure system. Figure 2 explicates an enlarged diffraction peak in the (101) plane in the $2 \theta$ regions situated between $35^{\circ}$ to $37.5^{\circ}$. From Fig. 2, the position of diffraction peak shifted towards the higher diffraction angle side with increasing the doping concentration of $\mathrm{Cu}^{2+}$ up to $18 \mathrm{wt} \%$. On further addition of $\mathrm{Cu}^{2+}(24 \mathrm{wt} \%)$, the diffraction angle has been shifted to a lower angle side of $2 \theta$. At lower concentrations $\mathrm{Cu}^{2+}$ ions are well incorporated within the host of $\mathrm{Zn}^{2+}$ substitutional positions due to the fact that of ionic radius. The lower ionic radii of $\mathrm{Cu}^{2+}\left(r_{i}=0.73 \AA\right)$ doped in $\mathrm{Zn}^{2+}\left(r_{i}=0.74 \AA\right)$ point host which issuing to decrease the interplanar distance ( $d$ values) resulting in the peak shift towards the higher angle. On higher wt\% more 
than $18 \%$, Cu2 + ions may be favored as lattice defects such as point vacancies $\left(\mathrm{V}_{\mathrm{Zn}}\right.$ or $\left.\mathrm{V}_{0}\right)$ or interstitial atoms which pronounces the more uniform distribution existent at around $18 \mathrm{wt} \%$ that exposes the solubility limit of $\mathrm{Cu}^{2+}$ in $\mathrm{ZnO}$ host matrix is $18 \mathrm{wt} \%$ [22]. Likewise, the intensity of diffraction peak monotonically decreased up to $18 \mathrm{wt} \%$ and then increases. Typically, the intensity of the diffraction pattern depends mainly on the atomic scattering factor. The atomic number of $\mathrm{Cu}^{2+}$ dopant $\left(\mathrm{Z}_{\mathrm{Cu}}=29\right)$ is slight lower than the host $\mathrm{Zn}^{2+}$ atom $\left(\mathrm{Z}_{\mathrm{Zn}}=30\right)$. In contrast, the peak intensity increased at $24 \mathrm{wt} \%$ of $\mathrm{Cu}^{2+}$ which also imperils the solubility of $\mathrm{Cu}^{2+}$ is $18 \mathrm{wt} \%$ in the $\mathrm{ZnO}$ host lattice [23]. The unit cell lattice constants of $\mathrm{ZnO}$ : $\mathrm{x} \% \mathrm{Cu}^{2+}(0,6,12,18$ and 24$)$ materials were also in accordance with the above findings. The Scherrer equation [24] was used to calculate the crystallite size of $\mathrm{ZnO}: \mathrm{x}^{0} \mathrm{Cu}^{2+}(0,6,12,18$ and 24) materials and the average crystallite size was approximately $14,14,15,23$ and $21 \mathrm{~nm}$.

Moreover, the in-depth structural inquiry was done by the Rietveld refinement method [25]. The software GSAS-II [26] was employed for the structural profile refinement. The Rietveld refined profiles of ZnO: $\mathrm{x} \%$ $\mathrm{Cu}^{2+}(0,6,12,18$ and 24) were manifested in Fig. 3 (a) - (e). The Rietveld profiles showed the high-grade fittings between calculated and observed data which intimated the consecration of the appropriate structure of the chosen system. From Fig. 3 (a) - (e), the horizontal blue line designates the difference between observed and calculated $X$-ray patterns. The small vertical red line signifies the corresponding Bragg positions. Table 1 compiled the refined structural parameters of the prepared $\mathrm{ZnO}: \mathrm{x}^{\circ} \mathrm{Cu}^{2+}(0,6,12$, 18 and 24) materials. From Table 1, the tiniest $\%$ of $R$ (reliability)-factor values are achieved which imparts good agreement of the Rietveld refinement.

Table 1

Refined structural parameters of $\mathrm{ZnO}$ materials

\begin{tabular}{|c|c|c|c|c|c|}
\hline Parameters/materials & Zno & $\mathrm{ZnO}: 6 \% \mathrm{Cu}^{2+}$ & $\mathrm{ZnO} 0: 12 \% \mathrm{Cu}^{2+}$ & $\mathrm{ZnO} 0: 18 \% \mathrm{Cu}^{2+}$ & $\mathrm{ZnO}: 24 \% \mathrm{Cu}^{2+}$ \\
\hline$a=b(\AA)$ & $3.2534(8)$ & $3.2499(13)$ & $3.2456(19)$ & $3.2416(19)$ & $3.2521(12)$ \\
\hline$c(\AA)$ & $5.2114(14)$ & $5.2057(21)$ & $5.2007(31)$ & $5.1931(31)$ & $5.2101(20)$ \\
\hline Volume $(\AA)^{3}$ & $47.77(2)$ & $47.61(3)$ & $47.44(5)$ & $47.25(5)$ & $47.72(3)$ \\
\hline Density $\left(\mathrm{g} / \mathrm{cm}^{3}\right)$ & 5.65 & 5.67 & 5.69 & 5.71 & 5.66 \\
\hline $\mathrm{R}_{\mathrm{obs}}(\%)$ & 1.08 & 1.16 & 1.28 & 1.12 & 1.14 \\
\hline GOF & 3.88 & 3.77 & 3.71 & 3.72 & 3.83 \\
\hline
\end{tabular}

\subsection{Morphological analysis}

For an adequate vacuum atmosphere (pressure level $<1.3 \times 10-4$ mbar) the surface morphology and corresponding elemental analysis with of synthesized $\mathrm{ZnO}: \mathrm{x}_{\mathrm{Cu}^{2+}}(0,6,12,18$ and 24$)$ are presented in Figs. 4 and 5 respectively. The slight dispersed granular like morphology was observed in undoped and 6 $\mathrm{wt} \%$ of $\mathrm{Cu}^{2+}$ doped $\mathrm{ZnO}$ material and the particle size at nearby $0.6 \mu \mathrm{m}$. After that, the dopant level 12 to 24 
wt\% of $\mathrm{Cu}^{2+}$ doped $\mathrm{ZnO}$ materials shows the agglomerated plate-like morphology with the particle size at approximately $1 \mu \mathrm{m}$.

The composition of elements presents in the prepared $\mathrm{ZnO}: \mathrm{x}_{\mathrm{Cu}^{2+}}(0,6,12,18$ and 24$)$ was assessed by EDS spectroscopy as shown in Fig. 5. The peak in the spectra designates the presence of an appropriate atom, and the peak intensity intimates the element concentration. The EDS spectrum fortifies the purity of $\mathrm{ZnO}$ and $\mathrm{Cu}^{2+}$ doped $\mathrm{ZnO}$ materials.

\subsection{Optical analysis}

Figure 6 shows the photoluminescence $(\mathrm{PL})$ excitation and emission spectra of $\mathrm{ZnO}: \mathrm{x}^{2} \mathrm{Cu}^{2+}(0,6,12,18$ and 24) phosphor. It is quite known the phosphor is a substance displaying luminescence. In this work, the synthesized materials are displays intensified luminescence performance. From Fig. 6, the excitation of each $\mathrm{ZnO}$ materials in the UV range consists of two parts, one is a broad band excitation originating from $250 \mathrm{~nm}$ which corresponds to valance band (VB) to conduction band (CB) transition. The broad excitation band reaches a slight sharpness at $385 \mathrm{~nm}$. The broad PL emission of all materials occurs from 430 to 600 $\mathrm{nm}$ maximum at $495 \mathrm{~nm}$, blue-green emission which corresponded to the recombination between electron and holes in the intermediate levels of $\mathrm{CB}$ and VB respectively. The PL emission intensity increases with increasing the $\mathrm{Cu}^{2+}$ dopant concentration up to $18 \mathrm{wt} \%$ then it decreases at $24 \mathrm{wt} \%$ of $\mathrm{Cu}^{2+}$. The optimum doping concentration of $\mathrm{Cu}^{2+}$ in $\mathrm{ZnO}$ is $18 \mathrm{wt} \%$. This is due to the fact that the higher energy intermediate vibration level is quenched by a mechanism called cross relaxation. There are numerous electrically neutral molecules (e.g. $\mathrm{ZnO}$ ) have been accommodates in the hexagonal $\mathrm{ZnO}$ lattice system. But the $\mathrm{Cu}^{2+}$ replaced by $\mathrm{Zn}^{2+}$, there is a chance of charge transfer to $\mathrm{Cu}^{2+}$ ions due to the lattice defects. The maximum PL intensity achieved at $18 \mathrm{wt} \%$ of $\mathrm{Cu}^{2+}$ incorporated $\mathrm{ZnO}$ which may ascribed to the possibility of less number of nonradiative recombination occur in the chosen material. In contrast the other dopant $\mathrm{wt} \%$ of $\mathrm{Cu}^{2+}$ may possibility of more number of nonradiative recombination which leads to the less intense PL emission [2730]. Y.S. Tver et al., [31] proposed that the dopant material such as transition metals, rare-earth metals and etc., substituted in the host lattice the more enhanced PL efficiency may only be achieved if the dipoledipole distance is equal to $5 \AA$. In this work the value of critical distance $\left(R_{c}\right)$ [32] is calculated. The critical distance

$$
R_{c}=2\left[\frac{3 V}{4 \pi x_{c} N}\right]^{1 / 3}
$$

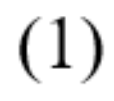

where $V$ is the volume of crystallographic unit cell (Table 1 ), $x_{c}$ is the critical concentration and $N$ is the number cations in the unit cell. The estimate $\mathrm{R}_{\mathrm{c}}$ values are presented in the Table 2 . From the Table 2 clearly shows the $18 \mathrm{wt} \%$ of $\mathrm{Cu}^{2+}$ doped $\mathrm{ZnO}$ material $\mathrm{R}_{\mathrm{c}}$ is at around $5.02 \AA$ which is more closer to the theoretical findings which may concerned the improved PL efficiency of chosen material. 
Table 2

Critical distance $\left(R_{c}\right)$

values of $\mathrm{ZnO}$ materials

\begin{tabular}{|ll|}
\hline Materials & $\mathrm{R}_{\mathrm{c}}(\AA)$ \\
\hline $\mathrm{ZnO}: 6 \% \mathrm{Cu}^{2+}$ & 7.25 \\
\hline $\mathrm{ZnO}: 12 \% \mathrm{Cu}^{2+}$ & 5.75 \\
\hline $\mathrm{Zn0}: 18 \% \mathrm{Cu}^{2+}$ & 5.02 \\
\hline $\mathrm{Zn0}: 24 \% \mathrm{Cu}^{2+}$ & 4.57 \\
\hline
\end{tabular}

Figure 7 displays the PL emission spectrum of $18 \mathrm{wt} \% \mathrm{Cu}^{2+}$ doped $\mathrm{ZnO}$ material. The emission spectrum is deconvoluted in three Gaussian peaks. The peak at $463 \mathrm{~nm}$ blue emission corresponding due to the recombination of electrons trapped in single ionized oxygen vacancies $\mathrm{V}_{0}^{*}$. The peak at $495 \mathrm{~nm}$ blue-green emission attained due to the doubly ionized oxygen vacancy $\mathrm{V}^{* \star}{ }_{0}$. The peak at $531 \mathrm{~nm}$ green-yellow emission originates from the intrinsic defects of oxygen interstitials $O_{i}[21,27]$.

Figure 8 depicts the commission international de l'Eclairage (CIE) [33] chromaticity coordinates of ZnO: $\mathrm{x} \%$ $\mathrm{Cu}^{2+}(0,6,12,18$ and 24) were estimated by CIE software. Table 3 depicts the $\mathrm{x}, \mathrm{y}$ CIE values of prepared materials. The $\mathrm{x}, \mathrm{y}$ coordinate of undoped $\mathrm{ZnO}$ and $6 \mathrm{wt} \%$ of $\mathrm{Cu}^{2+}$ doped $\mathrm{ZnO}$ were pointed in less intense blue-green portion. Other materials such as 12, 18 and $24 \mathrm{wt} \%$ of $\mathrm{Cu} 2+$ doped $\mathrm{ZnO}$ (x. y) coordinated placed at slight intensed green portion. The maximum red shift observed at $18 \mathrm{wt} \%$ which due to the higher PL emission intensity. The maximum red shift in $\mathrm{Cu}^{2+}$ doped $\mathrm{ZnO}$ material leads to potential candidate for the LED, display and other opto-electronics device applications.

Table 3

CIE values of $\mathrm{ZnO}$ materials

\begin{tabular}{|lll|}
\hline Materials & \multicolumn{2}{l|}{ CIE coordinate } \\
\cline { 2 - 3 } & $\mathrm{X}$ & $\mathrm{Y}$ \\
\hline $\mathrm{ZnO}$ & 0.220 & 0.53 \\
\hline $\mathrm{ZnO}: 6 \% \mathrm{Cu}^{2+}$ & 0.231 & 0.542 \\
\hline $\mathrm{Zn0}: 12 \% \mathrm{Cu}^{2+}$ & 0.252 & 0.576 \\
\hline $\mathrm{Zn0}: 18 \% \mathrm{Cu}^{2+}$ & 0.267 & 0.598 \\
\hline $\mathrm{Zn0}: 24 \% \mathrm{Cu}^{2+}$ & 0.261 & 0.572 \\
\hline
\end{tabular}

3.4. Photocatalysis 
The capacity of photocatalytic degradation of amaranth organic pollutant under direct sunlight of the asprepared $\mathrm{ZnO}: \mathrm{x}^{2} \mathrm{Cu}^{2+}(0,6,12,18$ and 24$)$ materials with different loadings of copper oxide are portrayed in Fig. 10. A plan of $\mathrm{C} / \mathrm{C}_{0}$ vs. time strongly affirms the photocatalysis ability stands unequivocally relying upon the idea of the materials. The $6 \mathrm{wt} \%$ of $\mathrm{Cu}^{2+}$ doped $\mathrm{ZnO}$ sample exhibit the minimum activity, when compared to another loading of copper oxide. With the increment in the stacking of copper oxide, the photocatalysis activity increases, and the $18 \mathrm{wt} \%$ of $\mathrm{Cu}^{2+}$ doped $\mathrm{ZnO}$ material displays the best exhibition. It ought to be noticed that during the photocatalysis test, the overall weight of the catalyst was determined and measured to incorporate the equivalent weight of copper oxide in every material, even though changes in their surface morphology. The least catalytic activity compared with $6 \mathrm{wt} \%$ of $\mathrm{Cu}^{2+}$ doped $\mathrm{ZnO}$ can be credited to the hint interaction of minimum amount of copper oxide with $\mathrm{ZnO}$. The correlation of absorption spectra by UV-vis results reveal that, the SEM image of $18 \mathrm{wt} \%$ of $\mathrm{Cu}^{2+}$ doped $\mathrm{ZnO}$, which is in acceptable concurrence with UV-vis. absorption information. The analytical and spectroscopic information is in brilliant concurrence with the noticed activity of photocatalysis pattern. The increment in the surface region is because of the underlying difference in copper oxide from low to optimized loading. Figure 9 shows the variety of band gab because of various loading of on $\mathrm{ZnO}$. All loadings show higher band gab associated and that of $\mathrm{ZnO}$ material. This is linked with the phenomenon of the quantum confinement effect. Among different loadings copper, the maximum loading material $24 \%$ display a bandgap value of $3.39 \mathrm{eV}$, which is near that of $\mathrm{ZnO}$ material. $18 \mathrm{wt} \%$ of $\mathrm{Cu}^{2+}$ doped $\mathrm{ZnO}$ material revealed the best active catalyst towards the direct sunlight facilitated degradation of dye. Other samples display a little higher band gap value. Remarkably, the best photocatalytic activity of $18 \%$, throws sunlight on the innovative sort of catalyst fabrication.

\section{Conclusion}

In summary, we fabricated $\mathrm{ZnO}: \mathrm{x}^{2} \mathrm{Cu}^{2+}(0,6,12,18$ and 24$)$ materials tailored via the thermal spreading method and characterized by PXRD, SEM, EDS, UV and PL techniques. Structural studies confirmed the synthesized $\mathrm{ZnO}$ and $\mathrm{Cu}^{2+}$ doped $\mathrm{ZnO}$ materials were absolute hexagonal crystal structure. The micro graphs analysis and element purity of prepared materials were investigated by SEM and EDS analysis respectively. The as-prepared $18 \mathrm{wt} \%$ of $\mathrm{Cu}^{2+}$ doped $\mathrm{ZnO}$ showed the excellent photocatalytic performance to degrade the Amaranth more than $96 \%$. The PL spectra revealed the $18 \mathrm{wt} \%$ of $\mathrm{Cu}^{2+}$ doped $\mathrm{ZnO}$ emits the intense blue-green emission when excited at $385 \mathrm{~nm}$. The obtained photocatalytic and photoluminescence performance revealed that $18 \mathrm{wt} \%$ of $\mathrm{Cu}^{2+}$ doped $\mathrm{ZnO}$ can be used as an optoelectronics application and superior photocatalytic material for degradation of organic dye Amaranth.

\section{Declarations}

\section{Acknowledgments}

The authors would like to express their gratitude to Deanship of Scientific Research at King Khalid University, Abha, Saudi Arabia for funding this work through Research Groups 
Program under Grant No. RGP.1/397/42.

\section{Declaration of conflict of interest}

None to declare

\section{Data availability statement}

The raw/processed data required to reproduce these findings cannot be shared at this time as the data also forms part of an ongoing study.

\section{References}

1. L. Jianping, L. Minrong, W. Jinnan, L. Jianjian, S. Hongwen, H. Maoxing, Report on Global Environmental Competitiveness (2013), 2014

2. F.M. Drumond Chequer, G.A.R. de Oliveira, E.R. Anastacio Ferraz, J. Carvalho, M.V. Boldrin Zanoni, D.P. de Oliveir, Textile Dyes: Dyeing Process and Environmental Impact, Eco-Friendly Text. Dye. Finish. (2013). doi:10.5772/53659

3. A. Montoya-Rodríguez, M.A. Gómez-Favela, C. Reyes-Moreno, J. Milán-Carrillo, E. González de, Mejía, Identification of bioactive peptide sequences from amaranth (amaranthus hypochondriacus) seed proteins and their potential role in the prevention of chronic diseases. Compr. Rev. Food Sci. Food Saf. 14, 139-158 (2015). doi:10.1111/1541-4337.12125

4. C.P. Silva, S. Marmitt, C. Haetinger, S. Stülp, Amaranth food dye photochemical and photoelectrochemical degradation: Experiments and mathematical modelling. WSEAS Trans. Syst. 7, 793-803 (2008)

5. L.Y. Wang, E.H. Song, T.T. Deng, Y.Y. Zhou, Z.F. Liao, W.R. Zhao, B. Zhou, Q.Y. Zhang, Luminescence properties and warm white LED application of a ternary-alkaline fluoride red phosphor K 2 NaAlF 6:Mn 4+ †. Dalt. Trans. 46, 9925-9933 (2017). doi:10.1039/c7dt02036h

6. J. Zhong, D. Chen, W. Zhao, Y. Zhou, H. Yu, L. Chen, Z. Ji, Garnet-based Li6CaLa2Sb2012:Eu3 + red phosphors: A potential color-converting material for warm white light-emitting diodes. J. Mater. Chem. C. 3, 4500-4510 (2015). doi:10.1039/c5tc00708a

7. M.M. Khin, A.S. Nair, V.J. Babu, R. Murugan, S. Ramakrishna, A review on nanomaterials for environmental remediation. Energy Environ. Sci. 5, 8075-8109 (2012). doi:10.1039/c2ee21818f

8. M. Fernndez-Garca, J.A. Rodriguez, M.O. Nanoparticles, Encycl. Inorg. Chem. (2009). doi:10.1002/0470862106.ia377

9. D. Sivaganesh, S. Saravanakumar, V. Sivakumar, K.S.S. Ali, E. Akapo, E. Alemayehu, R. Rajajeyaganthan, R. Saravanan, Structural, optical and charge density analysis of Al doped ZnO Materials. J. Mater. Sci. Mater. Electron. 30, 2966-2974 (2019). doi:10.1007/s10854-018-00574-5

10. X.J. Dai, Y.S. Luo, W.D. Zhang, S.Y. Fu, Facile hydrothermal synthesis and photocatalytic activity of bismuth tungstate hierarchical hollow spheres with an ultrahigh surface area. Dalt. Trans. 39, 34263432 (2010). doi:10.1039/b923443h 
11. S. Mohan, M. Vellakkat, A. Aravind, R. U, Hydrothermal synthesis and characterization of Zinc Oxide nanoparticles of various shapes under different reaction conditions. Nano Express 1, 030028 (2020). doi:10.1088/2632-959x/abc813

12. S.H. Khan, R. Suriyaprabha, B. Pathak, M.H. Fulekar, Development of zinc oxide nanoparticle by sonochemical method and study of their physical and optical properties, AIP Conf. Proc. 1724 (2016) 1-7. doi:10.1063/1.4945228

13. S.T. Navale, V.V. Jadhav, K.K. Tehare, R.U.R. Sagar, C.S. Biswas, M. Galluzzi, W. Liang, V.B. Patil, R.S. Mane, F.J. Stadler, Solid-state synthesis strategy of $\mathrm{ZnO}$ nanoparticles for the rapid detection of hazardous $\mathrm{Cl}$, Sensors Actuators. B Chem. 238, 1102-1110 (2017). doi:10.1016/j.snb.2016.07.136

14. M. Zare, K. Namratha, K. Byrappa, D.M. Surendra, S. Yallappa, B. Hungund, Surfactant assisted solvothermal synthesis of $\mathrm{ZnO}$ nanoparticles and study of their antimicrobial and antioxidant properties. J. Mater. Sci. Technol. 34, 1035-1043 (2018). doi:10.1016/j.jmst.2017.09.014

15. M.I. Khalil, M.M. Al-Qunaibit, A.M. Al-zahem, J.P. Labis, Synthesis and characterization of ZnO nanoparticles by thermal decomposition of a curcumin zinc complex. Arab. J. Chem. 7, 1178-1184 (2014). doi:10.1016/j.arabjc.2013.10.025

16. R. Bhaskar, A. Lakshmanan, S. Marimuthu, M.T. Jose, Mechanism of green luminescence in ZnO Mechanism of green luminescence in $\mathrm{ZnO}$, (2009) 1-4

17. S. Mahdavi, M. Jalali, A. Afkhami, Removal of heavy metals from aqueous solutions using Fe30 4, ZnO, and CuO nanoparticles, J. Nanoparticle Res. 14 (2012). doi:10.1007/s11051-012-0846-0

18. N.M. Alatawi, L. Bensaad, L. Soltane, A. Moulahi, I. Mjejri, F. Sediri, Enhanced solar photocatalytic performance of Cu-doped nanosized ZnO. Polyhedron 197, 115022 (2021)

19. R. Mohan, K. Krishnamoorthy, S.J. Kim, Enhanced photocatalytic activity of Cu-doped ZnO nanorods. Solid State Commun. 152, 375-380 (2012). doi:10.1016/j.ssc.2011.12.008

20. M. Sajjad, I. Ullah, M.I. Khan, J. Khan, M.Y. Khan, M.T. Qureshi, Structural and optical properties of pure and copper doped zinc oxide nanoparticles. Results Phys. 9, 1301-1309 (2018). doi:10.1016/j.rinp.2018.04.010

21. R. Raji, K.G. Gopchandran, ZnO:Cu nanorods with visible luminescence: Copper induced defect levels and its luminescence dynamics, Mater. Res. Express. 4 (2017). doi:10.1088/2053-1591/aa5762

22. S. Saravanakumar, J. Kamalaveni, M.P. Rani, R. Saravanan, Solubility of Mn stabilized cubic zirconia nanostructures. J. Mater. Sci. Mater. Electron. 25, 837-843 (2014). doi:10.1007/s10854-013-1654-8

23. S. Saravanakumar, D. Sivaganesh, K.S.S. Ali, M.C. Robert, M.P. Rani, R. Chokkalingam, R. Saravanan, Analysis of structural, optical and charge density distribution studies on Zn1-xMnxS nanostructures. Phys. B Condens. Matter. 545, 134-140 (2018). doi:10.1016/j.physb.2018.05.037

24. A.L. Patterson, The scherrer formula for $X$-ray particle size determination. Phys. Rev. 56, 978-982 (1939). doi:10.1103/PhysRev.56.978

25. H.M. Rietveld, The Rietveld method. Phys. Scr. (2014). doi:10.1088/0031-8949/89/9/098002

26. B.H. Toby, R.B. Von Dreele, GSAS-II: the genesis of a modern open-source all purpose crystallography software package, (2013) 544-549. doi:10.1107/S0021889813003531 
27. K. Vanheusden, W.L. Warren, C.H. Seager, D.R. Tallant, J.A. Voigt, B.E. Gnade, Mechanisms behind green photoluminescence in ZnO phosphor powders. J. Appl. Phys. 79, 7983-7990 (1996).

doi:10.1063/1.362349

28. A.K. Singh, G.S. Thool, P.R. Bangal, S.S. Madhavendra, S.P. Singh, Low temperature Mn doped ZnO nanorod array: Synthesis and its photoluminescence behavior. Ind. Eng. Chem. Res. 53, 9383-9390 (2014). doi:10.1021/ie500077v

29. B. Allabergenov, S.-H. Chung, S.M. Jeong, S. Kim, B. Choi, Enhanced blue photoluminescence realized by copper diffusion doping of ZnO thin films. Opt. Mater. Express. 3, 1733 (2013). doi:10.1364/ome.3.001733

30. R. Bhaskar, A.R. Lakshmanan, M. Sundarrajan, T. Ravishankar, M.T. Jose, N. Lakshminarayan, Mechanism of green luminescence in ZnO. Indian J. Pure Appl. Phys. 47, 772-774 (2009)

31. Y.S. Tver, Concentration Quenching of Luminescence of Rare-Earth lons in Chalcogenide Glasses, 29 (2003) 166-168

32. M. Janulevicius, P. Marmokas, M. Misevicius, J. Grigor, Luminescence and luminescence quenching of highly efficient $Y 2$ Mo 40 15: Eu 3 + phosphors and ceramics, (2016) 1-12. doi:10.1038/srep26098

33. T. Smith, J. Guild, J, The C.I.E. Colorimetric Standards, and their Use. Transaction of the Optical Society 33(3), 74-134 (1931)

\section{Figures}




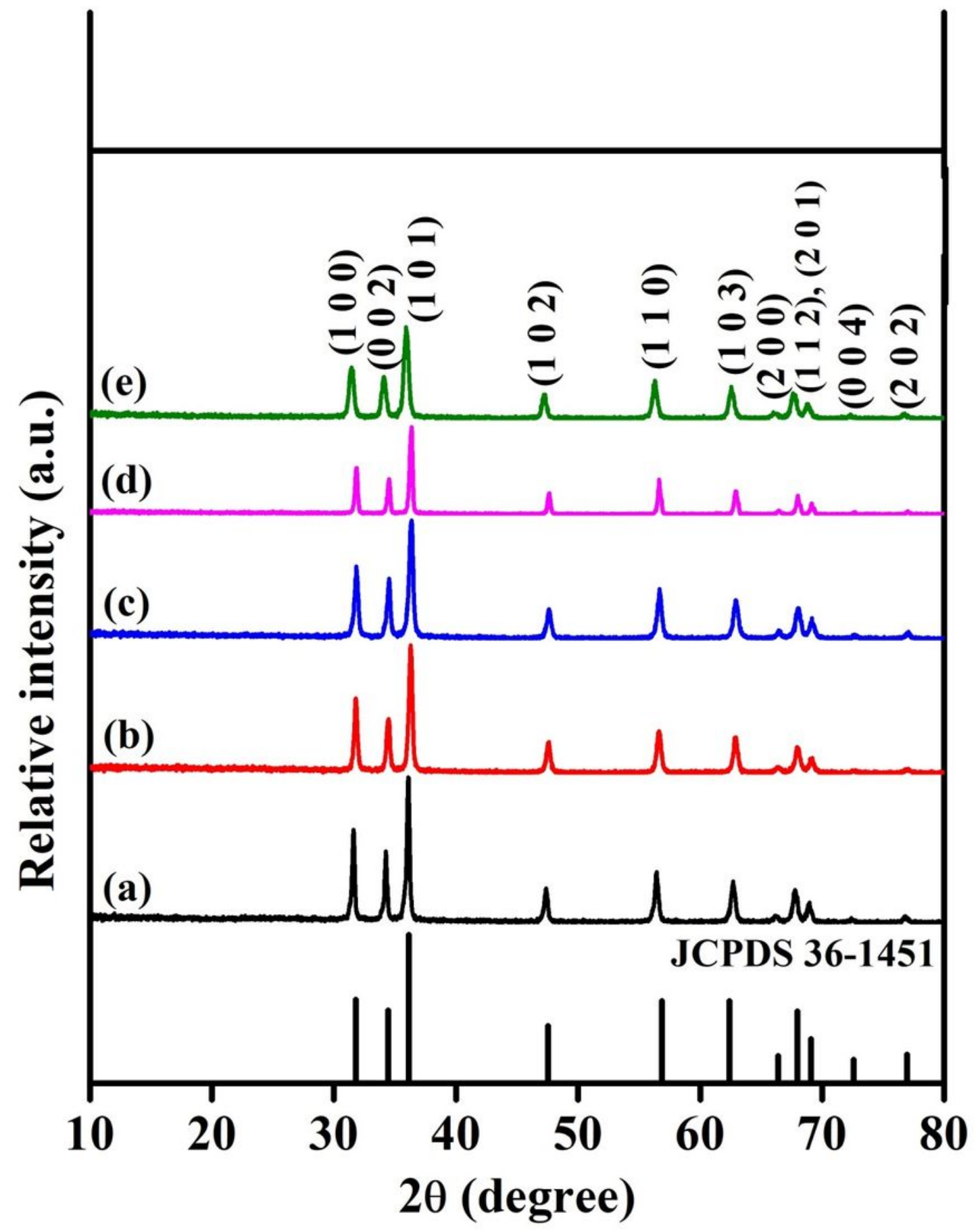

Figure 1

Observed PXRD profile of (a) ZnO, (b) ZnO:6\%Cu2+, (c) ZnO:12\%Cu2+, (d) ZnO:18\%Cu2+ and (e) ZnO:24\%Cu2+ 


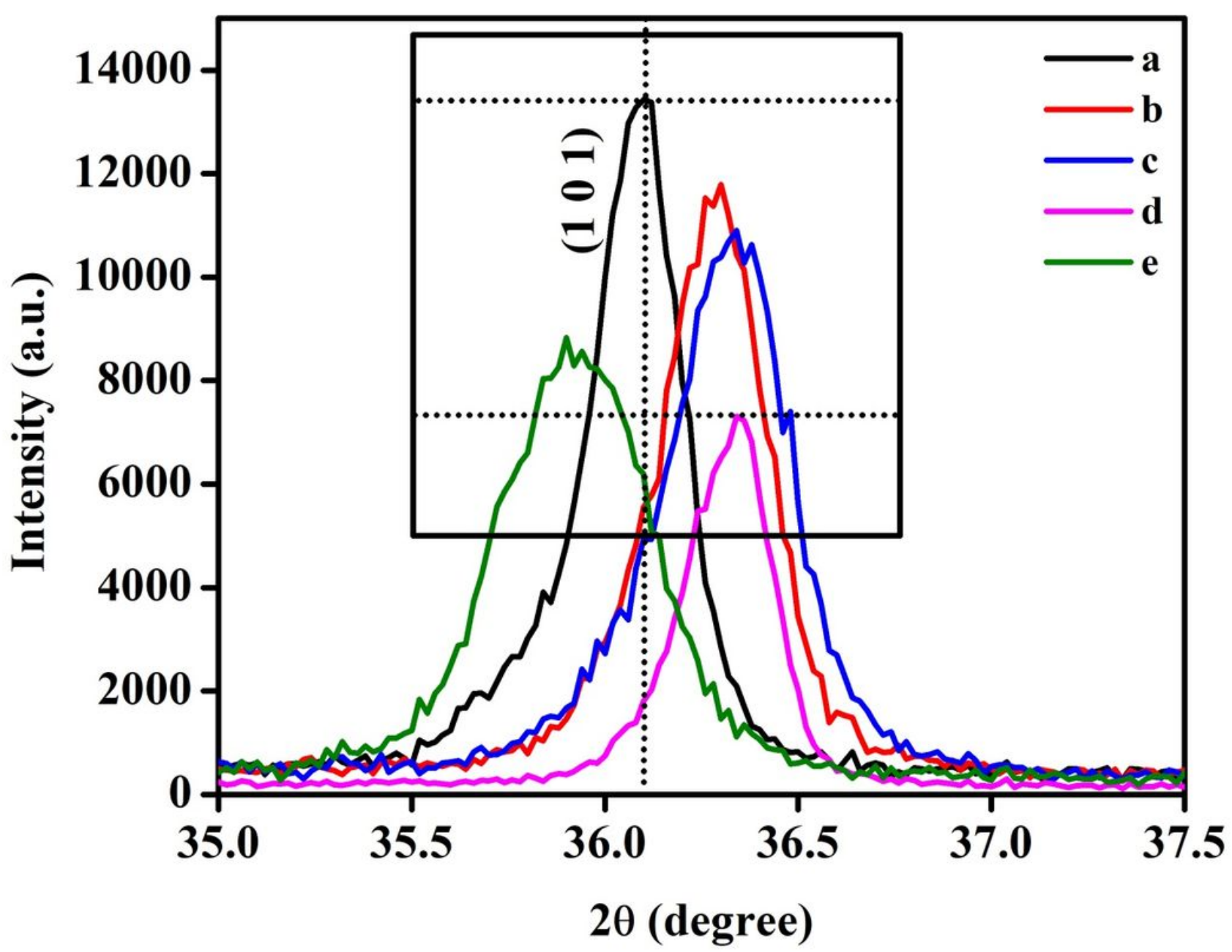

Figure 2

Enlarged PXRD pattern on (101) plane of (a) ZnO, (b) ZnO:6\%Cu2+, (c) ZnO:12\%Cu2+, (d) ZnO:18\%Cu2+ and (e) $\mathrm{ZnO}: 24 \% \mathrm{Cu} 2+$ 
(a)

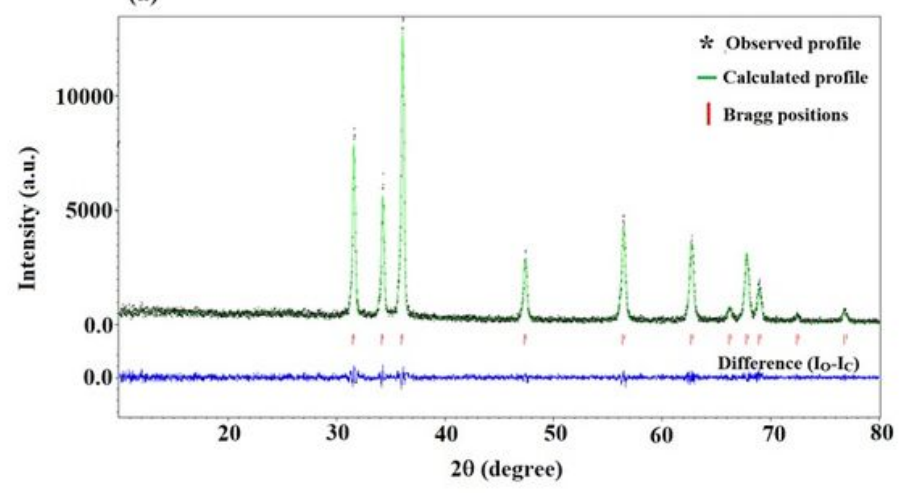

(c)

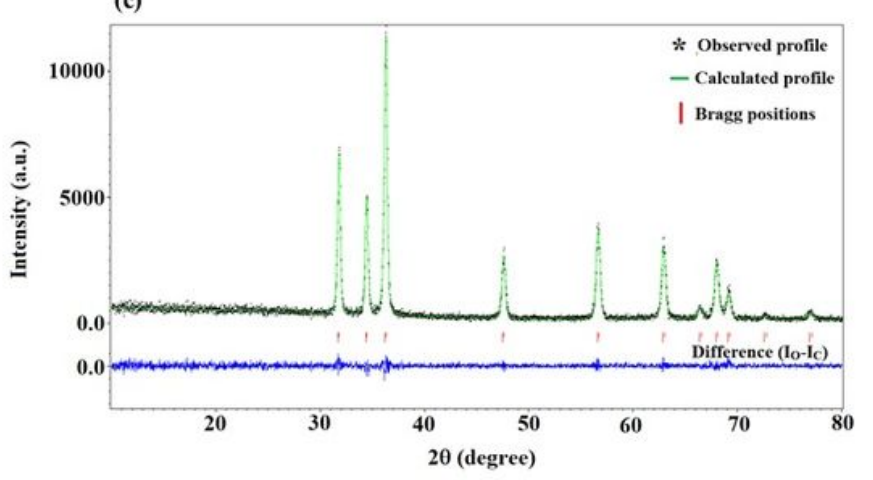

(b)

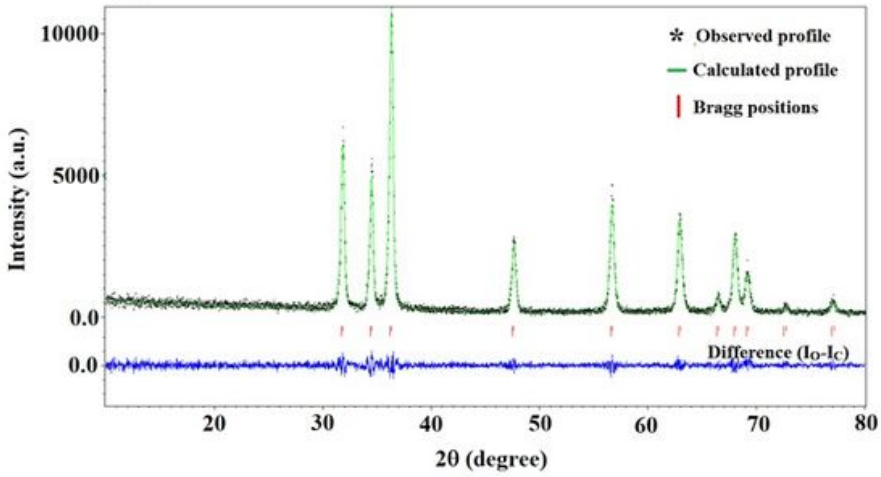

(d)

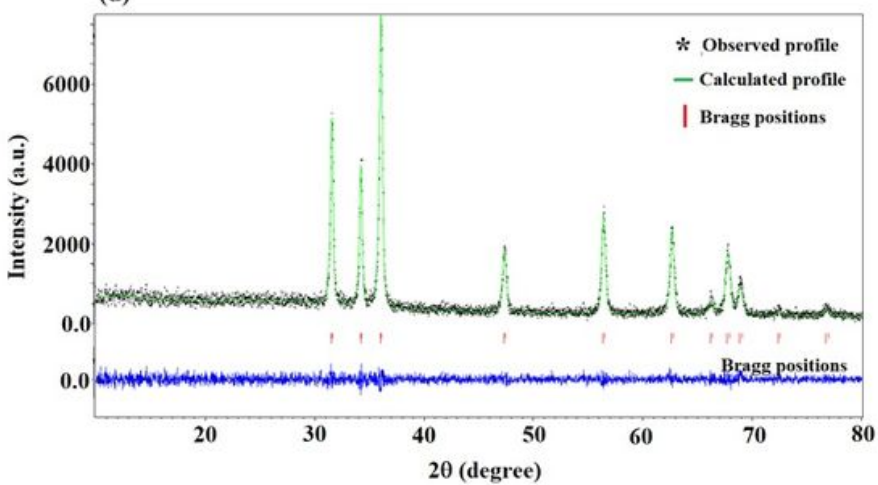

(e)

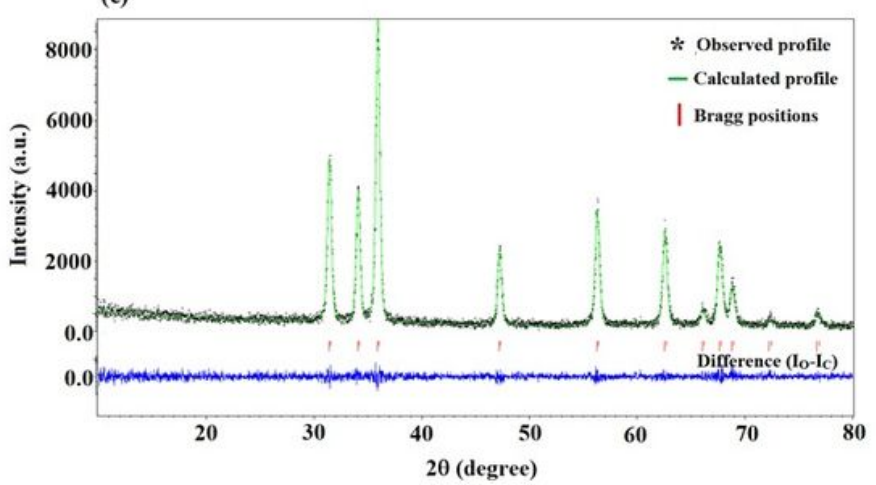

Figure 3

Refined profile of (a) ZnO, (b) ZnO:6\%Cu2+, (c) ZnO:12\%Cu2+, (d) ZnO:18\%Cu2+ and (e) ZnO:24\%Cu2+ 


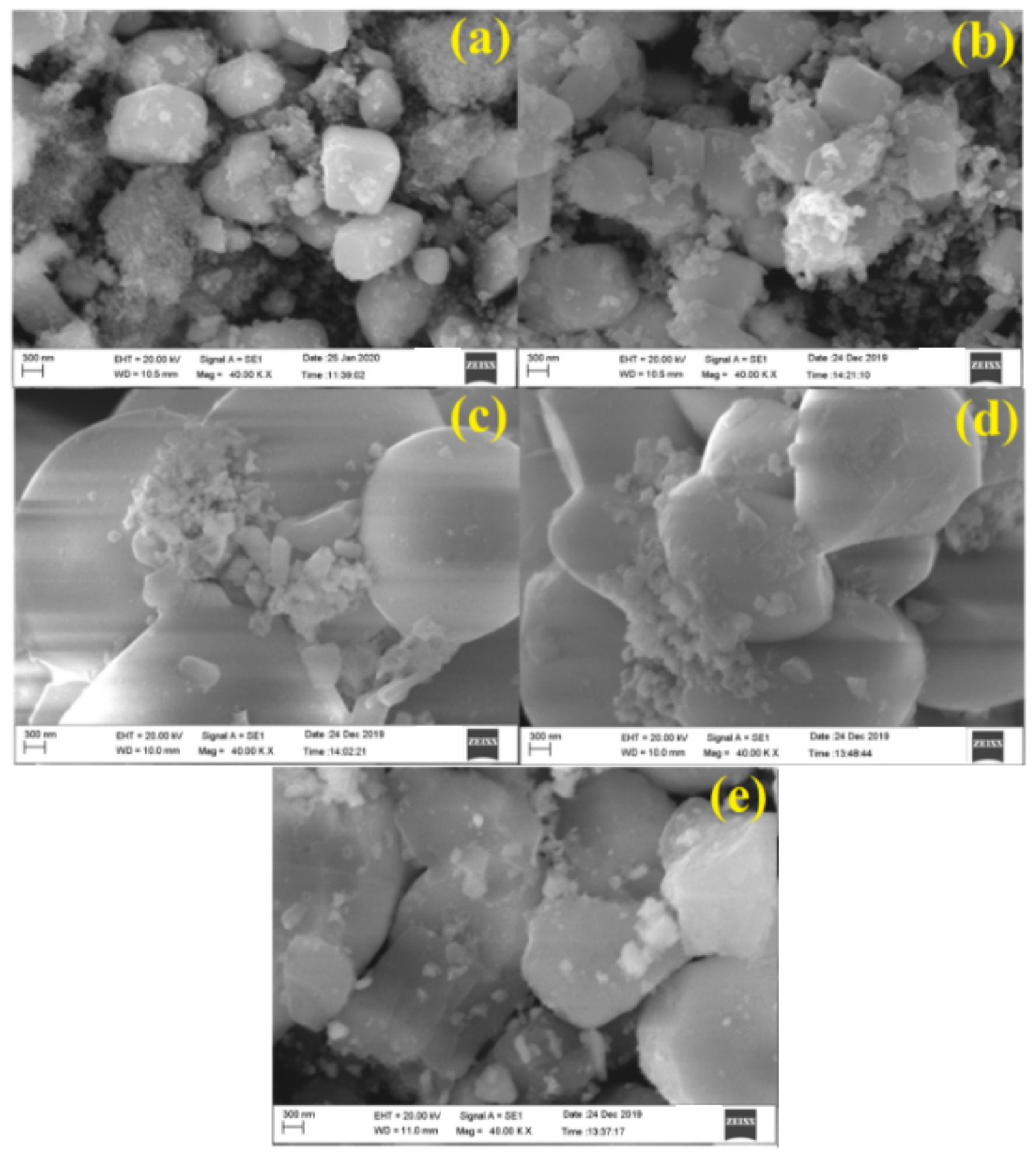

Figure 4

SEM micrographs of (a) ZnO, (b) ZnO:6\%Cu2+, (c) ZnO:12\%Cu2+, (d) ZnO:18\%Cu2+ and (e) ZnO:24\%Cu2+ 

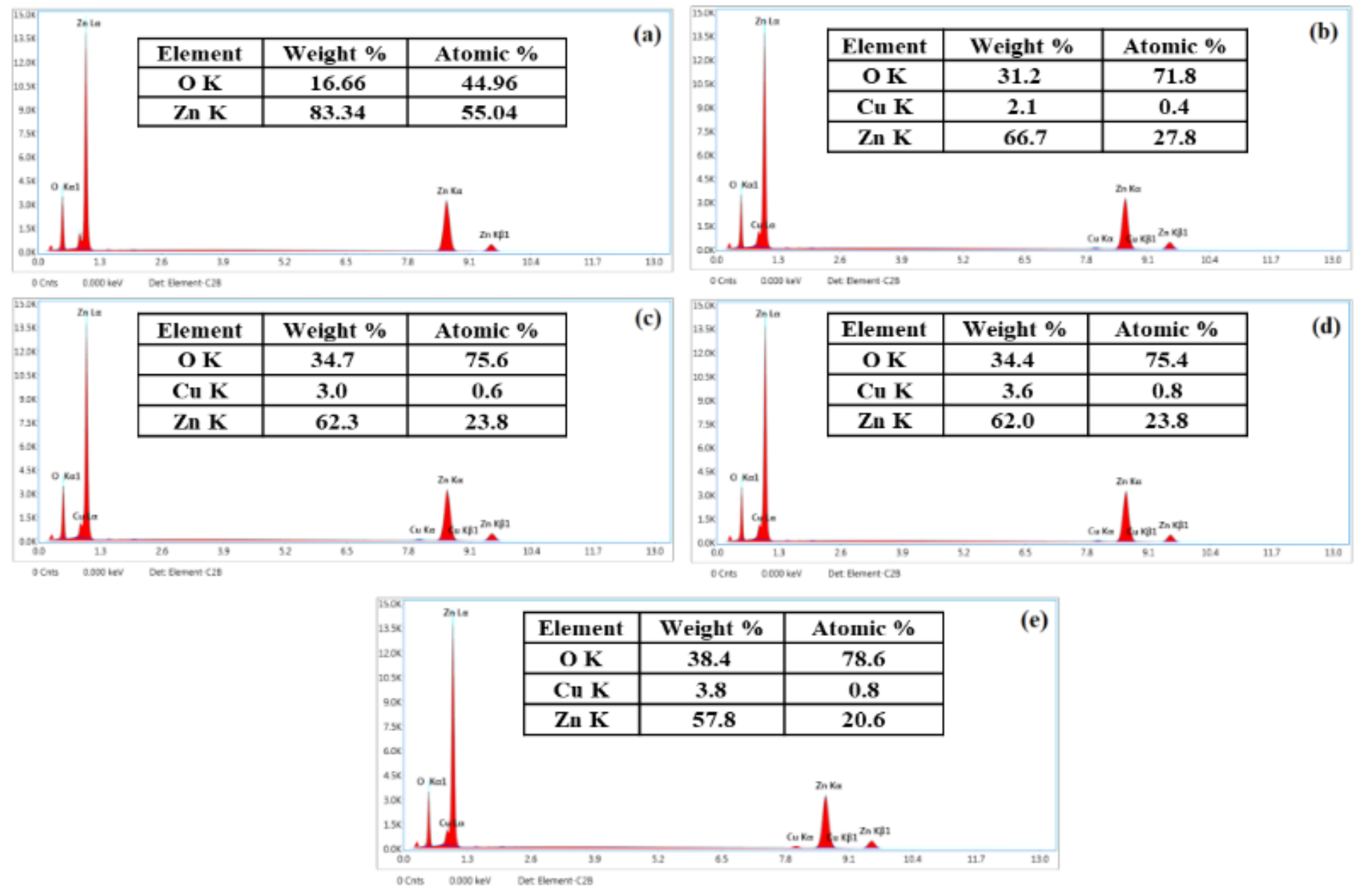

Figure 5

EDS spectrum of (a) ZnO, (b) ZnO:6\%Cu2+, (c) ZnO:12\%Cu2+, (d) ZnO:18\%Cu2+ and (e) ZnO:24\%Cu2+ 


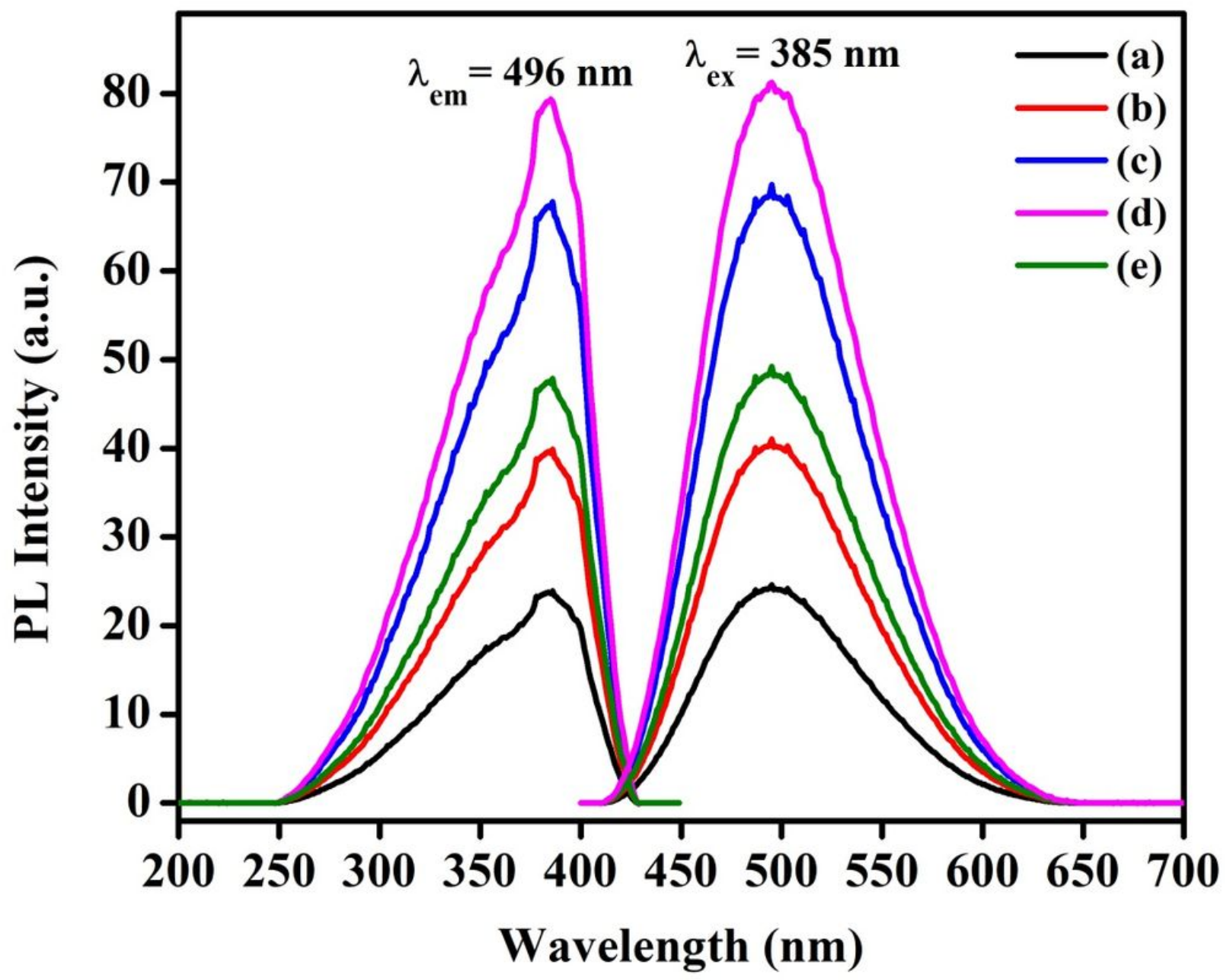

Figure 6

PL Spectra of (a) ZnO, (b) ZnO:6\%Cu2+, (c) ZnO:12\%Cu2+, (d) ZnO:18\%Cu2+ and (e) ZnO:24\%Cu2+ 


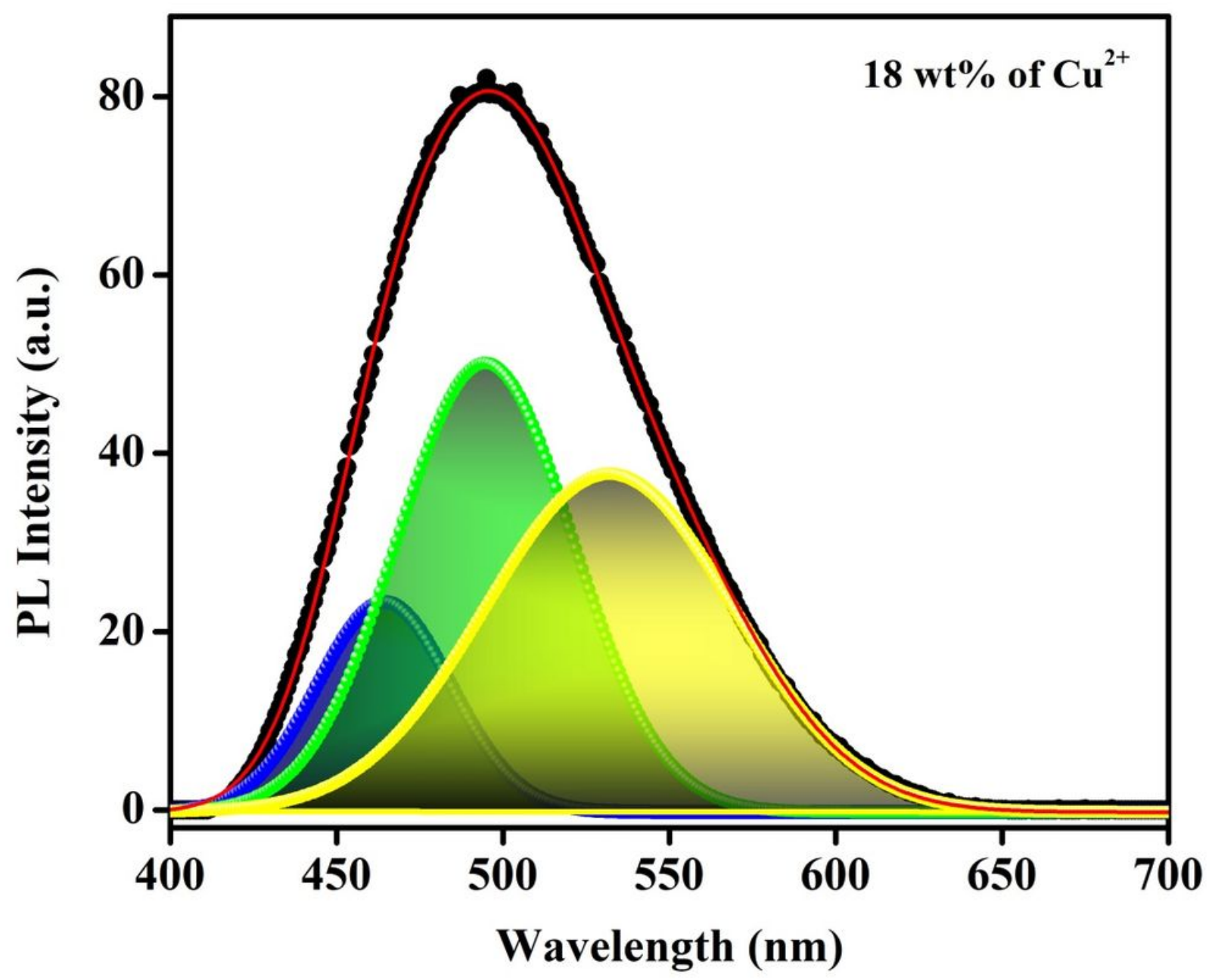

Figure 7

Gaussian fitted curves of $18 \%$ Cu2+ doped ZnO 


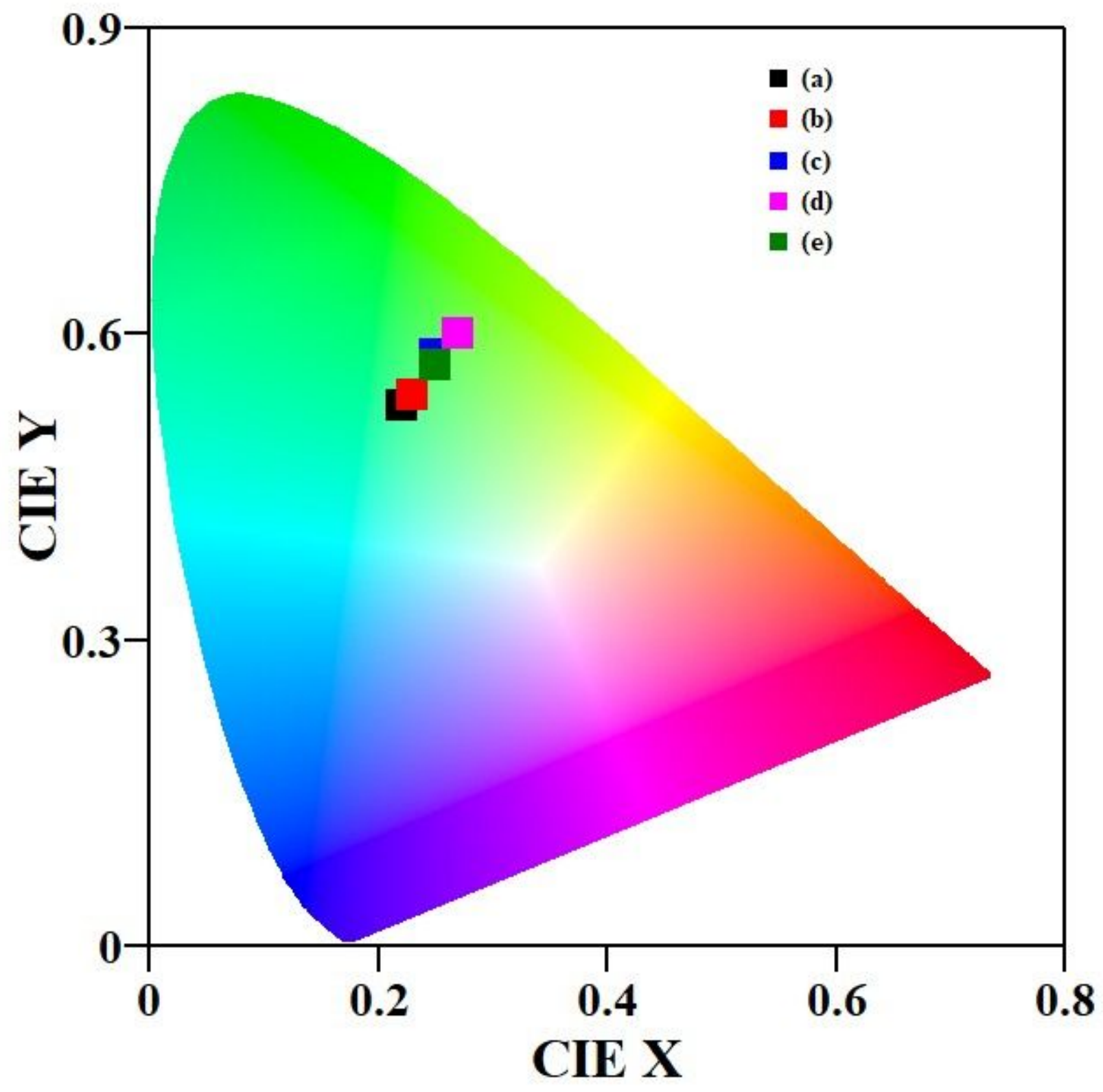

Figure 8

The Commission International de l'Eclairage (CIE) chromaticity coordinates of (a) ZnO, (b) ZnO:6\%Cu2+, (c) $\mathrm{ZnO}: 12 \% \mathrm{Cu} 2+$, (d) ZnO:18\%Cu2+ and (e) ZnO:24\%Cu2+ 


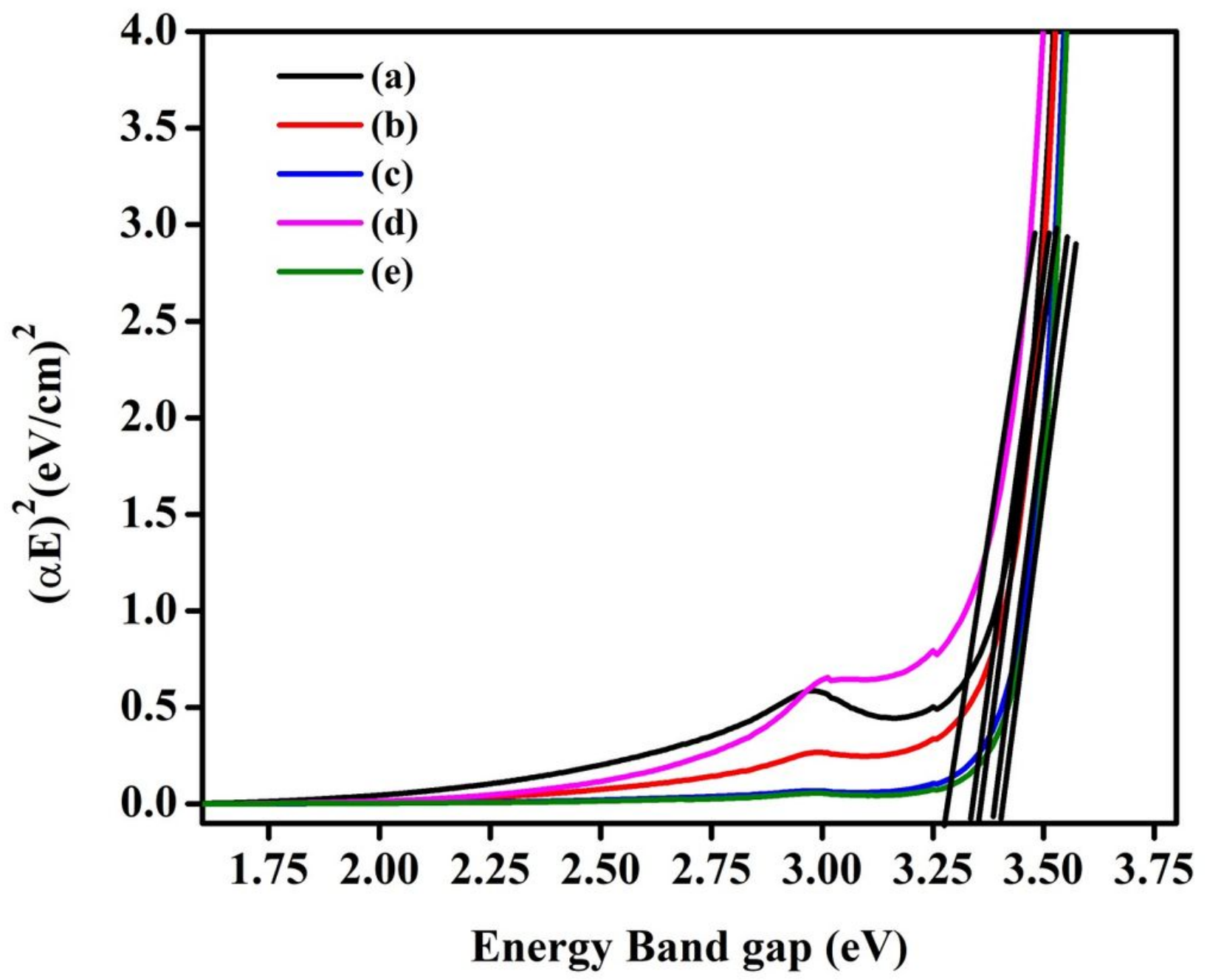

Figure 9

Energy band gap of (a) ZnO, (b) ZnO:6\%Cu2+, (c) ZnO:12\%Cu2+, (d) ZnO:18\%Cu2+ and (e) ZnO:24\%Cu2+ 


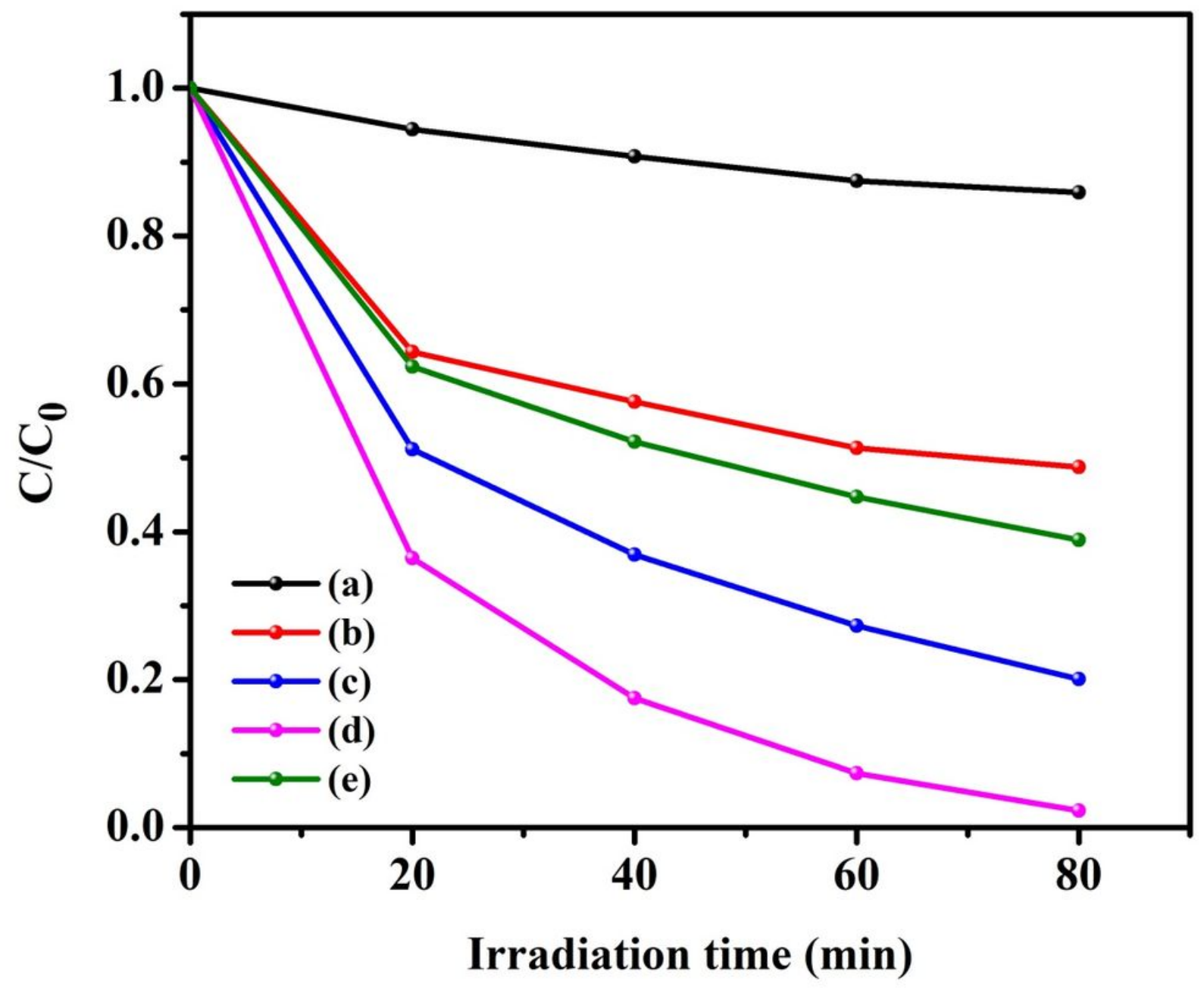

Figure 10

Photodegradation activity of $\mathrm{ZnO}: \mathrm{x} \% \mathrm{Cu} 2+(0,6,12,18$ and 24$)$ with various loading (a) without catalyst, (b) $\mathrm{ZnO}: 6 \% \mathrm{Cu} 2+$, (c) $\mathrm{ZnO}: 12 \% \mathrm{Cu} 2+$, (d) $\mathrm{ZnO}: 18 \% \mathrm{Cu} 2+$ and (e) $\mathrm{ZnO}: 24 \% \mathrm{Cu} 2+$ 